\title{
Students' Misconceptions On Mathematical Issue: A Study at The Pre-Service Student Teachers Program
}

\author{
A Yunita ${ }^{1}$, S Imelwaty ${ }^{2}$, Hamdunah $^{3}$ \\ ${ }^{1,2,3}$ STKIP PGRI Sumatera Barat \\ \{alfi_yunita@ymail.com¹, imelwaty05@stkip-pgri-sumbar.ac.id.2. hamdunahnasution@gmail.com³
}

\begin{abstract}
Basic mathematics is one of the compulsory courses for the preservice student teachers particularly for those who are prepared to teach science and mathematics for middle and high schools. Based on the test results which were obtained from the students at one of the teachers' education programs in West Sumatra province, Indonesia, there were still many students who had misconceptions in answering the given mathematical problems. The purpose of this study was to reveal the types and causes of the student misconceptions in solving the mathematical problems. This research is a descriptive study using quantitative data. The subject of this study was a small cohort of students majoring in Biology education department with 30 participants. The instruments were a test consisting of 9 description questions. The data were analyzed quantitatively and the types of their errors were classified. The results of the study showed that the students' misconceptions were found regarding the real number system problems, the inequalities and absolute values, the functions and graphs of functions, the systems of linear and nonlinear equations, the sequences and series which are divided into three, namely conceptual errors and principle errors and operating errors.
\end{abstract}

Keywords: Misconception, Mathematical Problems, Pre-service Student

\section{INTRODUCTION}

Mathematics is a science that is very important to be studied by every student, both from elementary school to university level. It is also learnt by the students who take mathematics as their major and for the students other than mathematics major. This is indicated that the students in the Biology Education at Teacher education programs offer basic mathematics as one of the courses that must be taken by the first-year student teachers. [2] also state that mathematics is a universal science that underlies technological development and has an important role in various disciplines. Therefore, it is not surprising if the curriculum particularly in Indonesia includes mathematics at every level of education ranging from basic education to tertiary education. The higher the level, the more complex the knowledge received so that it can support students' abilities to deal with various problems encountered. This is in line with [8] which states that mathematics is a field of life studies, which needs to be studied because the essence of mathematics is understanding the patterns of change that 
occur in the real world and in the human mind and the interrelationships between patterns holistically.

The basic mathematics course materials in the biology education program at the teacher education programs includes the real number systems, the inequalities and absolute values, the functions and graphs of functions, the systems of linear and nonlinear equations, the sequences and sequences, the trigonometry, the opportunities, the statistics, the geometry, the limits, the derivatives, and the integral. The test that had been carried out on the Biology Education department students indicated the students ${ }^{6}$ problems in answering the mathematical problems, especially in real number system material, inequalities and absolute values, functions and graph functions, systems of linear and nonlinear equations, rows and rows. According to [5], the learning environment activities that take place are not always in the same situation, there are things that are smooth, some are not smooth, there are students who quickly understand what is delivered by the lecturers and there are students who find it difficult to understand by lecturers. Students have high learning motivation and some are difficult to concentrate and do not have motivation, this is often the case in the learning process. As stated by [1] of the various fields of study taught in schools, mathematics is a field of study that is considered the most difficult by students, both for those without learning difficulties and especially for the students who have learning difficulties. This assumption continues at every level of education, so that this condition causes mathematics to become unpopular or being disliked by students, ignored and even ignored, then students experience learning difficulties.

According to [15], errors (misconceptions) of students can be used as guidelines to determine the extent to which students master and understand the material given. [11] states that "Misconceptions are generally accepted by students, apart from concepts scientifically accepted as true, and that are acquired by students by the end of the educational process". In addition, [6] state that "misconceptions result from the student's understanding of their previous experiences result from their interaction with their environment and they must be taken into account in educational practices to design appropriate instructional strategies that will impulse their evolution into more scientific-academic concepts". To this end, the researchers were interested in reveiling the types and causes of the student misconceptions in solving mathematical problems in the basic mathematics course.

There have been a number of studies that have examined the difficulties and misconceptions of the material in basic mathematics course. To name a few, the study by [3] on the inequality materials that the research subjects were the prospective PGSD [Elementary schools teachers program] teachers at the Muhammadiyah University of Sidoarjo consisting of 37 students. The instrument used was a description test consisting of 4 questions in one variable the linear inequality. According to the data obtained by the mistakes which were made by the students, it includes the conceptual, principle, and the operational errors. The factors that cause the errors were that the students did not understand the materials of the linear inequality prerequisites, the students did not understanding and solved the questions. The students were embarrassed to ask questions and express their opinions to the lecturers when interacting in class.

Furthermore, [3] also conducted a misconception study for absolute value materials in the form of equations and inequalities with the subject of research consisting of 138 PGSD UMSIDA students. He concluded the types of student difficulties including the inability to 
fully apply the concept of distance and the definition of absolute value so that the completion step is not complete; experience misunderstanding of absolute value terms; experiencing misconceptions in the form of assuming absolute values are always positive; experiencing difficulties in terms of conceptual, procedural, and algorithmic. The factors of causing the difficulties are the students memorizing formulas and theories without understanding the basic concepts of distance and definitions of absolute value; the students are accustomed to use the fast formulas as a provision to enter college. It is suggested for the lecturers of the basic mathematics course to instill the importance of basic concepts and make constructive learning habits.

Then the research of [9] where the study surveyed 73 students of the Sriwijaya University mathematics education program by giving several questions to test students' understanding of the concept of limits. Based on the results of the analysis of the student answers, it was concluded that most students had problems with conceptual understanding and the students also had misconceptions about limits. The first misconceptions identified was that students always use substitution methods to determine function limits at a point, but they did not check whether the function continues or not at its core. This means that they only used the substitution theories partially, because they did not assume that the substitution theory $f(x)=$ $f(c)$ works only if $(x)$ is defined at $x=c$. Another misconception was identified that some students always think that there must be an available variable $x$ in the function to determine the function limit. The study by [7] for integral materials concluded that students had difficulty learning in terms of mastering the concepts, skills and solutions.

The study by [12] on the mathematics courses for the students at the D2 PGSD UPI regarding the mathematical reasoning material, similarities and inequalities, relations and functions, permutations, combinations and opportunities, and data processing. It was found that there was a small number of students experienced difficulties, whereas for geometry transformation material and mathematical problem solving almost half of the students experienced difficulties. Followed by the study of [10] based on the test results of the mathematics students at Great Zimbabwe University in calculus course on the function material and function graphs, trigonometry, limits, derivatives and integrals, It was found that most errors were caused by the knowledge gaps in the basic algebra. We also note that the errors and the misconceptions in calculus are related to students' lack of advanced mathematical thinking because concepts in calculus are interrelated [14]. Also in this study, we highlight some common mistakes / errors that lecturers can make during the teaching process. Students who learn calculus often make the same mistakes and also lecturers who teach calculus have a pattern of errors.

Despite of number of studies on the students misconceptions on mathematical problems, there have been no studies on the misconception of basic mathematics course for the preservice student teachers who are prepared for teaching science such as Biology, thus this study has an aim to describe the misconceptions amongst the biology education students in the basic mathematics course, especially on the real number system material, inequalities and absolute values, functions and graphs of functions, systems of linear and nonlinear equations, sequences and sequences. 


\section{RESEARCH METHOD}

This study is a descriptive one using a quantitative data. The participants of this study were 30 pre-service student teachers of the biology education department at one of the teacher education programs in West Sumatra province, Indonesia. The instrument used for obtaining the data was a description test consisting of 9 description questions.. 9 questions were prepared on the mathematical problems, namely the problems which related to the material of real number systems, the inequalities and absolute values, the functions and graphs of functions, the systems of linear and nonlinear equations, the arithmetic sequences. Those students were asked to answer the given questions and then the researchers analyzed the students' answers. The percentage of the students answers were counted in order to describe on what problems that the students make most of. After that, the type of errors in solving the mathematical problems were classified into three types i.e. Errors in concepts, errors in principles and errors in operation.

\section{RESULT AND DISCUSSION}

After analyzing the data, it was found the percentage of the categories regarding the correct answers, the answers to fewer errors, the answers to many errors, the answers not according to the concept from the 30 students. The distribution of the percentage of the answers can be seen in table 1 .

Table 1. Percentage of the student answers the math problems

\begin{tabular}{cccccccccc}
\hline Category & 1 & 2 & 3 & 4 & 5 & 6 & 7 & 8 & 9 \\
\hline True (\%) & $50 \%$ & $6.7 \%$ & $3.3 \%$ & $0 \%$ & $0 \%$ & $10 \%$ & 13.3 & $6.7 \%$ & 43.3 \\
& & & & & & & $\%$ & $\%$ \\
Few errors (\%) & 16.7 & $40 \%$ & 16.7 & $6.7 \%$ & 10 & $20 \%$ & $6.7 \%$ & $30 \%$ & 16.7 \\
& $\%$ & & $\%$ & & $\%$ & & & & $\%$ \\
Many errors (\%) & 23.3 & 23.3 & 23.3 & 16.7 & 50 & 26.7 & $50 \%$ & $30 \%$ & 13.3 \\
& $\%$ & $\%$ & $\%$ & $\%$ & $\%$ & $\%$ & & & $\%$ \\
Answers not according & $10 \%$ & $30 \%$ & 56.7 & 76.7 & 40 & 43.3 & $30 \%$ & 33.3 & 26.7 \\
to concept (\%) & & & $\%$ & $\%$ & $\%$ & $\%$ & & $\%$ & $\%$ \\
\hline
\end{tabular}

From Table 1, it is evidence that the total percentage of the 'true' answers for numbers 1 to 9 is $14.8 \%$. Then for the 'few errors' answers, the total percentage is $18.2 \%$. The next one is the 'many errors' answers with the total percentage of $28.5 \%$. Finally, the total percentage of the 'answers not according to the concept' is $38.5 \%$. These results indicated that the students having a problem in understanding the concepts. It can be seen that the percentage of the answers does not match with the highest concept. The errors are classified into three types. They are errors in concepts, errors in principles and errors in operation. Each type of the errors are describes as follow.

The first one is the errors in concept which means that the errors in addition, subtraction or multiplication in non-like term. The errors occurred when the students did not understand the concept of adding the non-like term. The students were wrong in operating the non-like term form example the students summed two different terms of the variable by changing a constant 
into a group variable. It was also evidence that the respondents replaced the concept of variable by summing with the variable multiplication.

The next errors are in applying additive properties inequality. This error occurs when the respondent incorrectly applied the additive inequality as seen in Figure 1. The student did not change the negative sign on the variable to move the different segments.

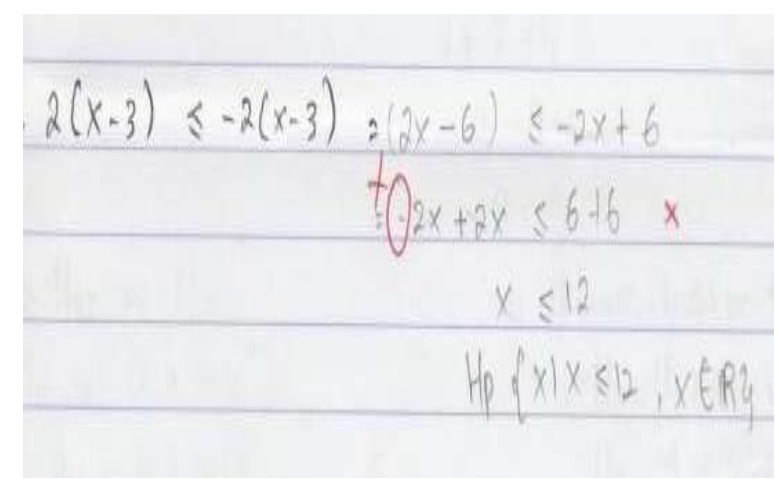

Figure1. Student's answer on the additive inequality

The errors also occurred in completing the settlement sets when the respondent misinterprets the completion of an inequality. The student made a mistake in writing an inequality without defining variables $\boldsymbol{x}$ in real numbers. Then the errors in writing number lines occurred when the students could not write down the real number line. The students made mistakes in the concept of making a real number line by determining the test point on the real number line.

Other errors were found in determining the boundaries by using the test points. This type of error occurred when the students make mistakes in taking the test point. They also made mistakes in the concept of taking the test point by taking the root as a test point. These data suggested that the students do not understand the intent of taking the test point. The errors in determining the area of origin and area of results were found when the students made mistakes in interpreting the denominator in a fraction. The errors also occurred in multiplying two negative numbers when the students made mistakes in multiplying the two negative numbers. They made mistakes in the concept of multiplying 2 negative numbers by adding the two numbers as well. However, the sign was correct.

It was also found the errors in applying the elimination and substitution method in which the students misunderstood the concept of a tribe which had been eliminated as seen in Figure 5. It is seen that the student made a mistake in the concept of eliminating a variable with the number $\mathrm{x}$ in the answer (a) and the variable $\mathrm{y}$ in the answer (b). 


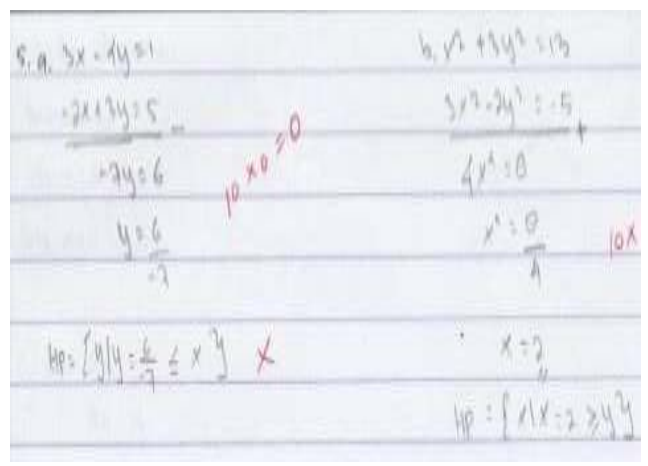

Figure5. The student's answer on applying the elimination and substitution method

The last but not the least, the errors in using arithmetic formulas was occurred when the students did not interpret the arithmetic sequence formula. They made mistakes in writing the arithmetic sequence formula to find the first and different term values. The type of errors in the principle were in addition, subtraction or multiplication occurred when the students made mistakes in interpreting an operator when eliminating a variable with a variable $\mathrm{y}$ as an example seen in Figure 6. The example of the error in the principle was made in determining the marks so that the term with the variable y can be eliminated.

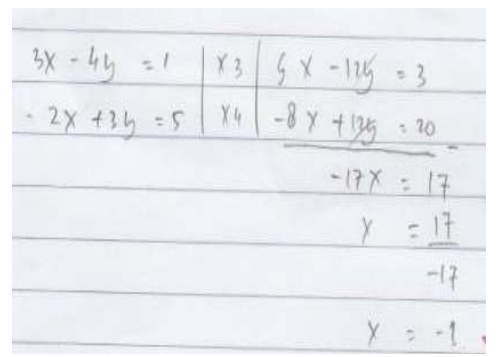

Figure 6. Student's error on the principle

The type of errors in operation was in addition, subtraction or multiplication operations. This type of error occurred when the students were not careful in completing an operation as seen in Figure 7. The students were assumed doing the operation carelessly in two term multiplication and subtraction operations.



Figure 7. Student's error in operation 


\section{CONCLUSION}

Based on the results of this study, it can be concluded that the misconceptions made by the students are in the conceptual, principle and operating errors. Possible reasons could be the causes of the errors such us intrinsic motivation. This could lead the students dislike mathematics. They might think mathematics is a scary subject, or the students are not careful enough in completing an addition, subtraction operation, multiplication and division. They might also do not understand the material holistically. Further qualitative study is suggested to be done in order to reveal the students problems in solving mathematical problems in basic mathematic course in teacher education program.

\section{ACKNOWLEDGEMENTS}

The researchers would like to expresses their deepest gratitude to the Directorate of Higher Education DP2M that has funded this research. We also thank to the Presidents of STKIP PGRI Sumatera Barat, its research unit that have given the researchers permission to conduct this research and also to the students who have participated in this study.

\section{REFERENCES}

[1] Abdurrahman, M. (2012). Children with Learning Difficulties: Theory, Diagnosis, and Remediation. Jakarta: PT. Rineka Cipta.

[2] Alfiyah, N \& Siswono, TYE (2014) Identification of Students' Metacognition Difficulties in Solving Mathematical Problems. Scientific Journal of Mathematics Education. Vol. 3, no. 2. pp. 131-138.

[3] Amir, MF (2015). Error Analysis of PGSD Students at Muhammadiyah University of Sidoarjo in Solving Linear Inequality Questions. Educational Journal, Vol. 1 No.2. ISSN. 2443-0455.

[4] Amir, MF (2017). Identification of Student Difficulties in Solving Open Ended Problems of Absolute Value Material Instructions for Writing Scripts. Mercumatika Journal: Journal of Mathematical Research and Mathematics Education. 2548-1819. Vol. 2, No. 1.pp. $1-1$

[5] Astuti and Sari, N. (2018). Analysis of Learning Difficulties in Algebraic Structure at Stkip Heroes Tuanku Tambusai. Journal of Mathematics Education. Vol. 12, No. 2. pp. $73-80$

[6] Cañada, F., González-Gómez, D., Airado-Rodríguez, D., Niño, L., \& Acedo, M. (2017). Change in elementary school students' misconceptions on material systems after a theoretical-practical instruction. International Electronic Journal of Elementary Education, 9 (3), 499-510

[7] Lestari, ASB (2015). Analysis of the Difficulties of Students of the Pgri Pasuruan Stkip Mathematics Education Study Program in the Integration Technique. Journal of Psychology, Vol. III, No. 1, p. 20-27.

[8] Martini, J. (2014). Learning Difficulties: Perspective, Assessment, and Management. Bogor: Ghalia Indonesia.

[9] Mulyono, B and Hapizah. (2017). Does Conceptual Understanding of Limit Partially Lead Students to Misconceptions? Journal of Physics Conference Series. 895012061

[10] Muzangwa, J and Chifamba, P. (2012). Analysis of Error and Misconceptions in The Learning of Calculus by Undergraduate Student. Acta Didactica Napocensia Journal. 
Vol 5 No.2.

[11] Nakhleh, M. (1992). Why some students don't learn Chemistry: Chemical misconceptions. Journal of Chemical Education, 69 (3), pp. 191-196.

[12] Priatna, D and Sumartono, F. O. (2009). Analysis of Difficulties of Students at the PGPI UPI D2 Program in Cibiru Campus in Mathematics Courses. EDUHUMANIORA: Journal of Basic Education, 1 (1).

[13] Saleem, H, Bagayko, D and. Kelley, EL (1999). Misconception and the Certainty of Response Index (CRI). Phys. Education. Vol. 34, No. 5, pp. 294-299.

[14] K. Saddhono and M. Rohmadi, "A Sociolinguistics Study on the Use of the Javanese Language in the Learning Process in Primary Schools in Surakarta, Central Java, Indonesia." Int. Edu. Stu., vol. 7 no.6 pp 25-30, 2014

[15] Widodo, SA (2012). The Process of Thinking Students in Resolving Mathematical Problems Based on the Dimensions of a Healer. Contribution of Mathematics and Mathematics Education in Building Teacher and StudentCharacter. 